\title{
TINJAUAN STRUKTUR BANGUNAN GEDUNG C2 RAWAT INAP RSUD CIMACAN
}

\author{
${ }^{1}$ Wiratna Tri Nugraha, ${ }^{2}$ Rio Diliawan Adilatama \\ Program Studi Teknik Sipil Fakultas Teknik Universitas Suryakancana \\ wiratnayk@yahoo.com, rioadilatama@gmail.com
}

\begin{abstract}
Abstrak
Peninjauan struktur Gedung C2 Rawat Inap RSUD Cimacan ini mengacu pada standar peraturan-peraturan perencanaan gedung Indonesia yang berlaku seperti, Tata Cara Perhitungan Struktur Beton Untuk Bangunan Gedung (SNI 03-2847-2002), Tata Cara Perencanaan Pembebanan Untuk Rumah dan Gedung (SNI 1727-1989) dan Tata Cara Perhitungan Struktur Beton Untuk Bangunan Gedung (SNI 032847-2002).

Perhitungan struktur menggunakan software SAP 2000 v.16. Struktur atas meliputi kontrol kekuatan pelat, balok, dan kolom. Yang meliputi gaya aksial, gaya geser dan momen. Pembebanan yang ditinjau untuk perencanaan elemen struktur adalah beban mati, beban hidup, dan beban gempa. .

Gaya-gaya dalam diperoleh dari output SAP 2000 v.16. Dan untuk dimensioning Balok, Kolom, dan Pelat menggunakan desain sendiri. Balok menggunakan dimensi $650 \times 300 \mathrm{~mm}$ dengan tulangan negatif 8D22 dan 4D22, tulangan positif 4D22 dan 8D22 dengan sengkang 30-150, untuk kolom menggunakan dimensi $550 \times 550 \mathrm{~mm}$ dengan tulangan 16D16, dan untuk pelat dengan tebal $120 \mathrm{~mm}$ lantai menggunakan tulangan 010-150. Mutu beton yang digunakan pada pelat adalah $30 \mathrm{Mpa}$, dan mutu baja yang digunakan pada pelat adalah 240Mpa. Untuk mutu beton pada balok dan kolom adalah sama yaitu 30Mpa, dan mutu baja 390Mpa. Seluruh desain balok, kolom, dan pelat dinyatakan aman dari Gaya Axial (Normal), Gaya Geser, dan Momen.
\end{abstract}

Kata kunci : Struktur bertulang, Balok, Kolom, Pelat, SAP v.16.

\section{a) PENDAHULUAN}

Peninjauan ulang struktur ini disebabkan karena pada beberapa desain kolom, balok dan pelat yang terlalu boros.

Hal ini tentunya perlu dikaji ulang mulai dari spesifikasi dan desain pada balok, kolom, dan pelat, perencanana arsitektur sampai pada perhitungan kekuatan struktur agar mendapatkan hasil yang lebih tepat namun dengan kekuatan yang sesuai standar untuk bangunan Rumah Sakit.

\section{TINJAUAN PUSTAKA}

\section{A. Balok}

Pada perencanaan gedung ini memiliki 2 jenis tumpuan pada balok dan pada pelat, yaitu satu ujung menerus dan kedua ujung menerus. Balok umumnya menjadi satu kesatuan yang monolit dengan pelat.

Pelat berlaku sebagai lapis sayap tekan yaitu sebagai komponen struktur yang bekerja pada dua arah lenturan saling tegak lurus, sedangkan balok berlaku sebagai badan. Fungsi balok adalah sebagai penyalur beban dari lantai ke kolom.

Dalam menentukan ukuran penampang balok, yaitu didasarkan pada tebal minimum (hmin) balok terhadap panjang bentang (h), maka dilakukan pendekatan berdasarkan SNI 03-2847-2002. Dengan L adalah bentang terpanjang, ketentuan ini berlaku untuk nilai fy $=400 \mathrm{MPa}$, sedangkan untuk fy selain nilai tersebut maka dikalikan dengan $(0,4+\mathrm{fy} / 700)$. Untuk lebar balok (bw), syaratnya adalah $b w=h / 2$ sampai dengan $2 h / 3$.

Pelimpahan beban merata pada balok-balok struktur dilakukan dengan metode amplop. Dengan cara ini, balok-balok struktur tersebut ada yang memikul beban trapesium dan beban segitiga. Untuk memudahkan perhitungan, beban trapesium dan beban segitiga diubah menjadi beban merata ukuran penampang pelat, maka diambil panel terbesar sebagai panel yang akan ditinjau. Untuk menentukan tebal pelat perlu diketahui terlebih dahulu nilai am.

\section{B. Pelat}

Pelat adalah elemen struktur yang mempunyai fungsi sebagai penopang langsung beban atau tumpuan beban. Dalam perencanaan gedung ini digunakan pelat dua arah. Pelat dua arah adalah pelat beton bertulang yang mempunyai angka perbandingan antara bentang yang panjang dengan yang pendek kurang dari 2. Pada pelat dua arah, 
momen yang diperhitungkan dalam dua arah Ly $<2$, Ly merupakan Lx bentang yang lebih panjang dan Lx adalah bentang yang pendek. Berdasarkan Pasal 11.5.3 SNI 03-2847-2002.

\section{Kolom}

Kolom adalah komponen struktur vertikal yang meneruskan beban dari balok atau pelat sehingga sampai pada pondasi. Keruntuhan pada suatu kolom merupakan penyebab utama keruntuhan total struktur gedung itu sendiri. Oleh karena itu dalam perencanaan gedung ini, kolom direncanakan lebih kuat daripada balok yang lebih dikenal dengan kolom kuat balok lemah.

Dalam perencanaan gedung ini, direncanakan kolom bujur sangkar dengan $\mathrm{b}=\mathrm{h}$. Berdasarkan SNI 03- 2847-2002 Pasal 10.10.2, lebar pelat efektif sebagai bagian dari balok-T tidak boleh melebihi $1 / 4$ bentang balok (bf $<1 / 4 \mathrm{~L}$ ). Sedangkan lebar efektif sayap dari masing-masing badan balok tidak boleh melebihi $(8 \mathrm{hf})$ dan tidak boleh melebihi (1/2 Ln) antara balok-balok yang bersebelahan.

\section{METODOLOGI}

Tahapan perhitungan struktur:

a) Menghitung pembebanan mati terhadap kolom, balok, dan pelat.

b) Menghitung pembebanan hidup pada kolom, balok dan pelat.

c) Menghitung beban gempa.

d) Menghitung gaya aksial, gaya geser dan momen menggunakan SAP 2000 v.16.

e) Menghitung dimensi kolom, balok dan pelat sebagai perhitungan akhir.

Metode yang digunakan dalam penelitian ini yaitu menggunakan kuisioner atau angket dan dilanjutkan dengan menghitung dengan menggunakan aplikasi yaitu SPSS.

\section{PEMBAHASAN}

\section{A. Hasil Perhitungan Pelat}

Menentukan koefisien momen pada pelat berbeda. Koefisien momen untuk plat 2 arah ditentukan berdasarkan tabel Momen di dalam plat persegi yang menumpu pada keempat tepinya akibat beban terbagi rata.

Pada kasus ini saya mengambil plat pada bentang tengah artinya menerus / terjepit elastis di keempat sisinya. Dengan nilai $\mathrm{K}=1.3$ dan dicocokkan ke tabel maka diperoleh nilai $X=31,19,69,57$. Momen perlu $(\mathrm{Mu})$

$$
\begin{aligned}
\text { - Mtx } & =0,001 \times \text { qu } \times \text { Lny } 2 \times \text { Ctx } \\
& =0,001 \times 8,297 \times 5,72 \times 69 \\
& =18,6 \mathrm{kNm} \\
\text { - } \quad \text { Mty } & =0,001 \times \text { qu } \times \text { Lnx } 2 \times \text { Cty }
\end{aligned}
$$

$$
\begin{aligned}
& =0,001 \times 8,297 \times 4,22 \times 57 \\
& =8,342 \mathrm{kNm}
\end{aligned}
$$

- $\operatorname{Mlx}=0,001 \times$ qu $x$ Lny $2 \times$ Clx

$$
=0,001 \times 8,297 \times 5,72 \times 31
$$$$
=8,357
$$

- $\quad$ Mly $=0,001 \times$ qu $\times$ Lnx2 x Cly

$$
\begin{aligned}
& =0,001 \times 8,297 \times 4,22 \times 19 \\
& =2,781 \mathrm{kNm}
\end{aligned}
$$

Menentukan jumlah dan luas tulangan: Tulangan lapangan arah X Mlx $=8,457 \mathrm{kNm}$ Diameter tulangan digunakan $(0 \mathrm{x})=10 \mathrm{~mm}$

- Panjang Efektif $(\mathrm{dx})=\mathrm{h}-$ decking - \% Ox $=120-20-(0,5 \times 10)=95 \mathrm{~mm}$

- $\mathrm{Rn}=\mathrm{Mu} /(\mathbf{O} \times \mathrm{x}$ b $\mathrm{x}$ d2 $)=8,357 \times 106 /$ $10 \times 1000 \times 952=0,926 \mathrm{~N} / \mathrm{mm} 2$

- $\mathrm{m}=\mathrm{Fy} / 0,85 \times \mathrm{fc}^{\prime}=240 / 0,85 \times 30=9,412$

Karena Mutu Baja = 240 mpa, Maka:

- $\mathrm{p} \min =0,025$

- $\mathrm{p}$ perlu $=1 / \mathrm{m}(1-\mathrm{V}(1-(2 \mathrm{Rn} \quad \mathrm{x} \mathrm{m}) / \mathrm{Fy}))=$ $1 / 9,412(1-\mathrm{V}(1-(2 \times 0,926 \times 9,412) / 240))=$ 0,004

- $\mathrm{pb}=91 \times(0,85 \times \mathrm{fc} / 240) \times(600 / 600+$ $\mathrm{Fy})=0,85 \times(0,85 \times 30 / 240) \times(600 / 600+$ 240) $=0,065$

- $\quad \mathrm{p} \max =0,75 \mathrm{pb}=0,049$

Karena $\mathrm{p}$ min $<\mathrm{p}$ perlu $<\mathrm{p}$ max

Maka dipakai $\mathrm{p}$ min

- $\mathrm{As}=\mathrm{p} \min \mathrm{x}$ b x dx $=0,025 \mathrm{x}$ $1000 \times 95=237,5 \mathrm{~mm} 2$

- $\mathrm{S}$ ada $=(0,25 \times \pi \times 102 \times 1000) / 237,5$ $=330,5 \mathrm{~mm}$

$\mathrm{S}$ pakai $=330 \mathrm{~mm}$

- As ada $=(0,25 \times \pi \times 102 \times 1000) / 330=$ $237,879 \mathrm{~mm}$

- Karena As ada > As, maka digunakan tulangan O10 - 150

- $\quad$ Tulangan lapangan arah Y Mly $=2,781$ $\mathrm{kNm}$

- Diameter tulangan digunakan $(\mathrm{Ox})=10 \mathrm{~mm}$

- Panjang Efektif $(\mathrm{dx})=\mathrm{h}$ - decking - \% Ox $=120-20-10-(0,5 \times 10)=85 \mathrm{~mm}$

- $\mathrm{Rn}=\mathrm{Mu} /\left(\begin{array}{lllll}( & \mathrm{x} & \mathrm{b} & \mathrm{x} & \mathrm{d} 2\end{array}\right)=$ $2,781 \times 106 / 1 \times 1000 \times 852=0,385 \mathrm{~N} / \mathrm{mm} 2$

- $\mathrm{m}=\mathrm{Fy} / 0,85 \times \mathrm{fc}^{\prime}=240 / 0,85 \times 30=9,412$ Karena Mutu Baja $=240$ mpa, Maka: $\mathrm{p}$ $\min =0,025$

- $\mathrm{p}$ perlu $=1 / \mathrm{m}(1-\mathrm{V}(1-(2 \mathrm{Rn} \times \mathrm{m}) / \mathrm{Fy}))=$ $1 / 9,412(1-\mathrm{V}(1-(2 \times 0,385 \times 9,412) / 240))=$ 0,0016

- $\mathrm{pb}=91 \times(0,85 \times$ fc /240) $\times(600 / 600+\mathrm{Fy})$ $=0,85 \times(0,85 \times 30 / 240) \times(600 / 600+240)$ $=0,065$ $\mathrm{p} \max =0,75 \mathrm{pb}=0,049$ 
Karena $\mathrm{p}$ min $>\mathrm{p}$ perlu $<\mathrm{p}$ max Maka dipakai $\mathrm{p}$ min

- $\mathrm{As}=\mathrm{p} \min \times \mathrm{b} \times \mathrm{dy}=0,0025 \times 1000 \times 85=$ $212,5 \mathrm{~mm} 2$

- $\mathrm{S}$ ada $=(0,25 \times 10 \times 102 \times 1000) / 212,5$ $=369,412 \mathrm{~mm}$

- $\mathrm{S}$ pakai $=370 \mathrm{~mm}$

- As ada $=(0,25 \times \pi \times 102 \times 1000) / 370=$ $212,162 \mathrm{~mm}$

Karena As ada > As, maka digunakan tulangan O10 - 150

Tulangan tumpuan arah $\mathrm{X} \mathrm{Mtx}=18,6 \mathrm{kNm}$

Diameter tulangan digunakan $(\mathrm{Ox})=10 \mathrm{~mm}$

- Panjang Efektif $(\mathrm{dx})=\mathrm{h}$-decking $-\%$ Ox $=$ $120-20-(0,5 \times 10)=95 \mathrm{~mm}$

- $\mathrm{Rn}=\mathrm{Mu} /(\mathrm{O} \times \mathrm{b} \times \mathrm{d} 2)=18,6 \times 106 / 1 \times 1000$ x $952=2,061 \mathrm{~N} / \mathrm{mm} 2$

- Panjang Efektif $(\mathrm{dx})=\mathrm{h}$-decking - \% Ox = 120-20- $(0,5 \times 10)=95 \mathrm{~mm}$

- $\mathrm{Rn}=\mathrm{Mu} /(\mathrm{O} \times \mathrm{x}$ b x d2 $)=18,6 \times 106 / 1 \mathrm{x}$ $1000 \times 952=2,061 \mathrm{~N} / \mathrm{mm} 2$

- $\mathrm{m}=\mathrm{Fy} / 0,85 \times \mathrm{fc}=240 / 0,85 \times 30$ $=9,412$

Karena Mutu Baja $=240$ mpa, Maka $: \mathrm{p} \min =$ 0,025 ,

- $\mathrm{p}$ perlu $=1 / \mathrm{m}(1-\mathrm{V}(1-(2 \mathrm{Rn} \times \mathrm{m}) / \mathrm{Fy}))=$ $1 / 9,412(1-\mathrm{V}(1-(2 \times 2,061 \times 9,412) / 240))=$ 0,009 .

- $\mathrm{pb}=91 \times(0,85 \times \mathrm{fc} / 240) \times(600 / 600+\mathrm{Fy})$ $=0,85 \times(0,85 \times 30 / 240) \times(600 / 600+240)$ $=0,065$

- $\mathrm{p} \max =0,75 \mathrm{pb}=0,049$

Karena $\mathrm{p}$ min $<\mathrm{p}$ perlu $<\mathrm{p}$ max

- Maka dipakai $\mathrm{p}$ min As $=\mathrm{p} \min \mathrm{x} b \mathrm{x} \mathrm{dx}=0,025 \times 1000 \mathrm{x}$ $95=237,5 \mathrm{~mm} 2$

- $\mathrm{S}$ ada $=(0,25 \times \pi \times 102$ 1000) $/ 237,5=330,5 \mathrm{~mm}$

$\mathrm{S}$ pakai $=330 \mathrm{~mm}$

- As ada $=(0,25 \times \pi \times 102 \times$ $1000) / 330=237,879 \mathrm{~mm}$

Karena As ada > As, maka digunakan tulangan O10 - 150 .

- Tulangan tumpuan arah Y Mly =8,342 kNm

- Diameter tulangandigunakan $(\mathrm{Ox})=10 \mathrm{~mm}$

- Panjang Efektif $(\mathrm{dx})=\mathrm{h}$ - decking $1 / 2 \mathrm{Ox}=120-20-10-(0,5 \mathrm{x} 10)=85 \mathrm{~mm}$

- $\mathrm{Rn}=\mathrm{Mu} /\left(\begin{array}{lllll}(\mathrm{O} & \mathrm{x} & \mathrm{b} & \mathrm{x} & \mathrm{d} 2\end{array}\right)=8,342 \times 106 /$ $1 \mathrm{x} 1000$ x $852=1,155 \mathrm{~N} / \mathrm{mm} 2$

- $\mathrm{m}=\mathrm{Fy} / 0,85 \mathrm{x} \mathrm{fc^{ \prime }}=240 / 0,85 \times 30=9,412$

Karena Mutu Baja $=240 \mathrm{mpa}$, Maka:

- $\mathrm{p} \min =0,025$
- $\mathrm{p}$ perlu $=1 / \mathrm{m}(1-\mathrm{V}(1-(2 \mathrm{Rn} \quad \mathrm{x} \mathrm{m}) / \mathrm{Fy}))=$ $1 / 9,412(1-\mathrm{V}(1-(2 \times 1,155 \times 9,412) / 240))=$ $0,0049 \mathrm{pb}=91 \times(0,85 \times \mathrm{fc} / 240) \times(600 / 600$ Fy $)=0,85 \times(0,85 \times 30 / 240) \times(600 / 600+$ $240)=0,065$

- $\mathrm{p} \max =0,75 \mathrm{pb}=0,049$

Karena $\mathrm{p} \min >\mathrm{p}$ perlu $<\mathrm{p}$ max Maka dipakai $\mathrm{p}$ min

- $\mathrm{As}=\mathrm{p} \min \mathrm{x} \mathrm{b} \times \mathrm{dy}=0,0025 \times 1000 \times 85$ $=212,5 \mathrm{~mm} 2$

- $\mathrm{S}$ ada $=(0,25 \times \pi \times 102 \times 1000) / 212,5$ $=369,412 \mathrm{~mm}$

- $\mathrm{S}$ pakai $=370 \mathrm{~mm}$

- As ada $=(0,25 \times \pi \times 102 \times 1000) / 370=$ $212,162 \mathrm{~mm}$

Karena As ada > As, maka digunakan tulangan $010-150$.

\section{B. Hasil Perhitungan Balok}

Tabel 1. Perhitungan Balok

\begin{tabular}{l|l|l|l}
\hline & \multicolumn{3}{c}{ Balok As C } \\
\hline \multirow{2}{*}{ Lantai } & \multirow{2}{*}{ Balok } & \multicolumn{2}{c}{ Aksial } \\
\cline { 3 - 4 } & 1.A.1 & 3731,737 & $-53,327$ \\
\hline 2 & 2.A.1 & 3731,737 & $-73,9126$ \\
\hline 3 & 3.A.1 & 3731,737 & $-80,5866$ \\
\hline 4 & 4.A.1 & 3731,737 & $-142,264$ \\
\hline 5 & 5.A.1 & 3731,737 & $-161,993$ \\
\hline Atap & 6.A.1 & 3731,737 & $-183,052$ \\
\hline
\end{tabular}

\begin{tabular}{c|c|c|c}
\hline \multicolumn{4}{|c}{ Balok As C } \\
\hline \multirow{2}{*}{ Lantai } & \multirow{2}{*}{ Balok } & \multicolumn{2}{|c}{ Geser } \\
\cline { 3 - 4 } 1 & $1 . B .1$ & 367,031 & 284,5504 \\
\hline 2 & $2 . B .1$ & 367,031 & 308,2928 \\
\hline 3 & $3 . B .1$ & 367,031 & 284,9172 \\
\hline 4 & $4 . B .1$ & 367,031 & 271,629 \\
\hline 5 & $5 . F .1$ & 367,031 & 264,9793 \\
\hline Atap & $6 . G .1$ & 367,031 & 204,6689 \\
\hline \multicolumn{4}{|c}{ Balok As 13 } \\
\hline \multirow{2}{*}{ Lantai } & \multirow{2}{*}{ Balok } & \multicolumn{3}{|c}{$\mathrm{Geser}$} \\
\cline { 3 - 4 } & $1 . \mathrm{dVn}(\mathrm{kN})$ & $\mathrm{Vu}(\mathrm{kN})$ \\
\hline 1 & 1.1 & 367,031 & 284,5504 \\
\hline 2 & $2 . B .1$ & 367,031 & 308,2928 \\
\hline
\end{tabular}




\begin{tabular}{c|c|c|c}
\hline 3 & 3. B.1 & 367,031 & 284,9172 \\
\hline 4 & $4 . B .1$ & 367,031 & 271,629 \\
\hline 5 & $5 . F .1$ & 367,031 & 264,9793 \\
\hline Atap & $6 . G .1$ & 367,031 & 204,6689 \\
\hline
\end{tabular}

\begin{tabular}{c|c|c|c}
\hline \multirow{2}{*}{ Lantai } & \multirow{2}{*}{ Kolom } & \multicolumn{2}{|c}{ Momen } \\
\cline { 3 - 4 } $\begin{array}{c}\text { Basem } \\
\text { ent }\end{array}$ & 0 B 1 & $1.268,479$ & 207,7695 \\
\hline 1 & 1 C 1 & $1.268,479$ & 278,8693 \\
\hline 2 & 2 B 3 & $1.268,479$ & 249,2998 \\
\hline 3 & 3 C 3 & $1.268,479$ & 215,5306 \\
\hline 4 & 4 C 3 & $1.268,479$ & 150,7416 \\
\hline 5 & 5 A 3 & $1.268,479$ & 106,6203 \\
\hline \multicolumn{3}{|c}{ Kolom As 13 }
\end{tabular}

\begin{tabular}{c|c|c|c}
\hline \multicolumn{4}{|c}{ Balok As C } \\
\hline \multirow{2}{*}{ Lantai } & \multirow{2}{*}{ Balok } & \multicolumn{2}{|c}{ Momen } \\
\cline { 3 - 4 } & & $\mathrm{dMn}(\mathrm{kN})$ & $\mathrm{Mu}(\mathrm{kN})$ \\
\hline 1 & $1 . \mathrm{B} .3$ & 458,635 & 355,1008 \\
\hline 2 & 2. B.3 & 458,635 & 422,9558 \\
\hline 3 & $3 . \mathrm{C} .1$ & 458,635 & 375,9692 \\
\hline 4 & 4.F.1 & 458,635 & 339,7738 \\
\hline 5 & 5.F.1 & 458,635 & 301,6083 \\
\hline Atap & 6.G.1 & 458,635 & 204,6689 \\
\hline
\end{tabular}

\section{Hasil Perhitungan Kolom}

Tabel 2. Perhitungan Kolom

\begin{tabular}{|c|c|c|c|}
\hline \multicolumn{4}{|c|}{ Kolom As C } \\
\hline \multirow{2}{*}{ Lantai } & \multirow{2}{*}{ Kolom } & \multicolumn{2}{|c|}{ Aksial } \\
\hline & & $\mathrm{dPn}(\mathrm{kN})$ & $\mathrm{Pu}(\mathrm{kN})$ \\
\hline $\begin{array}{c}\text { Basem } \\
\text { ent }\end{array}$ & 0 D 1 & $4.620,9$ & $2.579,3487$ \\
\hline 1 & $1 \mathrm{D} 1$ & $4.620,9$ & 2.101 .4807 \\
\hline 2 & $2 \mathrm{D} 1$ & $4.620,9$ & $1.608,6827$ \\
\hline 3 & $3 \mathrm{D} 1$ & $4.620,9$ & $1.152,0403$ \\
\hline 4 & $4 \mathrm{D} 1$ & $4.620,9$ & 699,3559 \\
\hline 5 & $5 \mathrm{D} 1$ & $4.620,9$ & 266,122 \\
\hline \multicolumn{4}{|c|}{ Kolom As C } \\
\hline \multirow{2}{*}{ Lantai } & \multirow{2}{*}{ Kolom } & \multicolumn{2}{|c|}{ Geser } \\
\hline & & $\mathrm{dVn}(\mathrm{kN})$ & $\mathrm{Vu}(\mathrm{kN})$ \\
\hline $\begin{array}{c}\text { Basem } \\
\text { ent }\end{array}$ & 0 B 1 & 521,174 & 190,5304 \\
\hline 1 & $1 \mathrm{~B} 1$ & 521,174 & 145,6798 \\
\hline 2 & $2 \mathrm{~B} 1$ & 521,174 & 123,3772 \\
\hline 3 & $3 \mathrm{~B} 1$ & 521,174 & 118,236 \\
\hline 4 & $4 \mathrm{~F} 1$ & 521,174 & 83,7488 \\
\hline 5 & $5 \mathrm{~A} 1$ & 521,174 & 57,7784 \\
\hline \multicolumn{4}{|c|}{ Kolom As C } \\
\hline
\end{tabular}

\begin{tabular}{cc|c|c}
\hline \multirow{2}{*}{ Lantai } & \multirow{2}{*}{ Kolom } & \multicolumn{2}{|c}{ Aksial } \\
\cline { 3 - 4 } & & $\mathrm{dPn}(\mathrm{kN})$ & $\mathrm{Pu}(\mathrm{kN})$ \\
\hline $\begin{array}{c}\text { Basem } \\
\text { ent }\end{array}$ & \multirow{2}{*}{ 0 G 1 } & $4.620,9$ & 154,5092 \\
\hline 1 & 1 D 1 & $4.620,9$ & 146,507 \\
\hline 2 & 2 D 2 & $4.620,9$ & 173,95076 \\
\hline 3 & 3 F 1 & $4.620,9$ & 121,6068 \\
\hline 4 & 4 F 1 & $4.620,9$ & 99,5042 \\
\hline 5 & 5 G 1 & $4.620,9$ & 58,2854
\end{tabular}

\begin{tabular}{|c|c|c|c|c|c|c|}
\hline \multicolumn{7}{|c|}{ Kolom As 13} \\
\hline \multirow{2}{*}{ Lantai } & \multirow{2}{*}{\multicolumn{2}{|c|}{ Kolom }} & \multicolumn{4}{|c|}{ Geser } \\
\hline & & & \multicolumn{2}{|c|}{$\mathrm{dVn}(\mathrm{kN})$} & \multicolumn{2}{|c|}{$\mathrm{Vu}(\mathrm{kN})$} \\
\hline $\begin{array}{c}\text { Basem } \\
\text { ent }\end{array}$ & \multicolumn{2}{|c|}{$0 \mathrm{H} 1$} & \multicolumn{2}{|c|}{521,174} & \multicolumn{2}{|c|}{$2.579,3487$} \\
\hline 1 & \multicolumn{2}{|c|}{$1 \mathrm{~B} 1$} & \multicolumn{2}{|c|}{521,174} & \multicolumn{2}{|c|}{2.101 .4807} \\
\hline 2 & \multicolumn{2}{|c|}{$2 \mathrm{~B} 1$} & \multicolumn{2}{|c|}{521,174} & \multicolumn{2}{|c|}{$1.608,6827$} \\
\hline 3 & \multicolumn{2}{|c|}{3 B 1} & \multicolumn{2}{|c|}{521,174} & \multicolumn{2}{|c|}{$1.152,0403$} \\
\hline 4 & \multicolumn{2}{|c|}{$4 \mathrm{~B} 1$} & \multicolumn{2}{|c|}{521,174} & \multicolumn{2}{|c|}{699,3559} \\
\hline 5 & \multicolumn{2}{|c|}{$5 \mathrm{H} 1$} & \multicolumn{2}{|c|}{521,174} & \multicolumn{2}{|c|}{266,122} \\
\hline \multicolumn{7}{|c|}{ Kolom As 13} \\
\hline \multirow{2}{*}{\multicolumn{2}{|c|}{ Lantai }} & \multirow{2}{*}{\multicolumn{2}{|c|}{ Kolom }} & \multicolumn{3}{|c|}{ Mome } \\
\hline & & & & $\mathrm{dMn}$ & $\mathrm{N})$ & $\mathrm{Mu}(\mathrm{kN})$ \\
\hline \multicolumn{2}{|c|}{$\begin{array}{c}\text { Basem } \\
\text { ent }\end{array}$} & \multicolumn{2}{|c|}{0 B 1} & \multicolumn{2}{|c|}{$1.268,479$} & 211,7246 \\
\hline \multicolumn{2}{|l|}{1} & \multicolumn{2}{|c|}{$1 \mathrm{~B} 1$} & \multicolumn{2}{|c|}{$1.268,479$} & 332,2599 \\
\hline \multicolumn{2}{|l|}{2} & \multicolumn{2}{|c|}{$2 \mathrm{H} 3$} & \multicolumn{2}{|c|}{$1.268,479$} & 324,981 \\
\hline 3 & & & & 1.268 & 479 & 258,4011 \\
\hline 4 & & & & 1.268 & 479 & 225,2622 \\
\hline 5 & & & & 1.268 & 479 & 152,2098 \\
\hline
\end{tabular}




\section{KESIMPULAN DAN SARAN}

\section{A. Kesimpulan}

Berdasarkan analisis data dan analisis struktur yang dilakukan oleh penyusun secara terurai di bab-bab sebelumnya mulai dari analisis gambar kerja sampai analisis perhitungan pembebanan serta analisis struktur kontrol imensioning, maka dapat ditarik kesimpulan sebagai berikut:

1. Dalam perencanaan bangunan, arsitektur dapat berpengaruh terhadap struktur bangunan sendiri.

2. Analisis struktur dilakukan dengan dua dimensi, dan hanya dilkukan pada 2 portal terekstrim baik arah X dan arah Y (portal AS C untuk arah X dan portal AS 13 utuk arah Y)

3. Dari hasil kontrol dimensioning untuk pelat lantai yang dilakukan pada bentang terekstrim (4500 x $3000 \mathrm{~mm})$.

4. Hasil analisis dan perhitungan semua elemen struktur dinyatakan aman.

\section{B. Saran}

Berdasarkan hasil dari pengerjaan tugas akhir ini penulis memiliki beberapa saran untuk penulisan karya tulis berikutnya supaya didapatkan hasil penulisan penelitian yang lebih baik.

Untuk lebih tepatnya perhitungan stuktur analisa konstruksi ini masih perlu ditinjau dengan perhitungan asli dari perencanaan konsultan, namun narena keterbatasan bahan dan materi data yang didapat dari pihak yang bersangkutan, penulisan tugas akhir ini tidak sampai ke perbandingan dengan perhitungan asli konsultan Penulisan ini menggunakan metode Standar Perencanaan Ketahanan Gempa Untuk Struktur Bangunan Gedung (SNI-1726- 2002), Tata Cara Perencanaan Pembebanan Untuk Rumah dan Gedung (SNI 1727-1989) dan Tata Cara Perhitungan Struktur Beton Untuk Bangunan Gedung (SNI 03-2847-2002). Sehingga penelitian ini tidak menjamin kedepannya untuk dijadikan pedoman, saran dari penulis adalah untuk selalu menggunakan metode yang terbaru yang telah ditetapkan pemerintah, sehingga tugas akhir ini dijadikan perbandingan dan referensi saja.

\section{DAFTAR PUSTAKA}

Aminudin , Hanifah S. 2017. Laporan Tugas Akhir Tin $\}$ auan Struktur Apartemen Poris 88 Tangerang.

Dipohusodo, Istimawan. 1994. Struktur Beton Bertulang. Jakarta: Gramedia.

https://anekabangunan.com/tabel- konversi-umurbeton/ (30/11/2020)

https://www.arsitur.com/2019/02/perbedaanoneway-slab-dan-two-way-slab.html (30/11/2020)

https://www.dis.or.id/industri/kons truksi-baja/ $(16 / 03 / 2019)$

https://www.etsworlds.id/2020/01/kurva-teganganregangan-stress- strain.html (30/11/2020)

http://www.repository.unissula.aSc.id/6754/1/4\%2 0BAB\%20I.pdfS (16/03/2019)

https://www.scribd.com/doc/1377 82337/strukturPortal-Bergoyang- Dan-Tak-Bergoyang (02/09/2019)

https://www.situstekniksipil.com/2017/11/tutorialperhitungan-kolom-dengan.html (10/10/2019)

https://www.slideshare.net/AryoBimantoro1/conto h-kerjaan-struktur-beton-bertulang-2 $(10 / 10 / 2019)$

https://www.slideshare.net/KetutSwandana/pertem uan-v-15794147 (20/06/2019)

https://www.slideshare.net/perkasa45/materikuliah-beton- sederhana (30/11/2020)

https://www.spesialiskonstruksi.com/2018/12/kons truksi-baja- komposit.html (16/03/2019)

https://wiryanto.blog/2018/12/12/ beban-hidupatap-konstruksi- pabrik/ (10/10/2019)

SNI-03-1729-2002-Baja.SNI.Tata Cara Perencanaan Struktur Baja Untuk Bangunan Gedung (13/10/2020) 